\section{INFLUENCIA DE KANT NA FILOSOFIA DO DIREITO}

\section{Delfim Mendes Silveira}

Prof. de Filosofia do Direito da Faculdade de Direito de Pelotas da Universidade do Rio Grande do Sul.

1 - Poucas vêzes, na história do pensamento humano, o vulto de um filósofo terá exercido, direta ou indiretamente, tão grande influência, seja no ambiente de sua época, seja no reestudo, no reexame dos problemas, das orientações, das tendências que lhe foram subseqüentes, quanto Emanuel Kant, o velho professor, que se tornou o maior e o mais profundo expoente do relativismo subjetivo.

A filosofia moderna deve-lhe um dos seus grandes impulsos. A própria História da Civilização, pelo seu ideal de paz e de solidaridariedade, o acolhe no pôsto elevado, que se reserva àqueles que souberam engrandecer o gênero humano.

2 - A modernidade assinala uma grande revolução, em todos os setores da vida, assim nas ciências físicas e naturais, como na esfera do pensamento puro, na reflexão filosófica, nos sistemas e métodos imperantes, nas idéias e nos ideais, no objeto das perquirições, na forma diferente das construções mentais.

“À proporção que a Europa ia progredindo na organização social, - escreve Balmes - manifestavam-se novas tendências intelectuais, notando-se em diferentes sentidos um forte espírito de oposição à filosofia de Aristóteles que dominava exclusivamente nas escolas. A queda de Constantinopla trouxe à Europa alguns sábios fuoitivos e com êles as doutrinas de Platão e outros amigos; assim se propagou cada vez mais o espírito de renovação filosófica, mormente quando o auxiliava também o espírito de controvérsia, característico dos gregos; o que se não vinha muito a propósito para o verdadeiro progresso, servia pelo menos de poderoso ariete contra as escolas peripatéticas."
Havia, sobretudo, ao lado, ou melhor, de par com as demais transformações, um anseio incontido de renovação intelectual. Tendências novas teriam de ser imprimidas ao pensamento, dando origem a novas construções filosóficas, que viessem ocupar o lugar vago com o abandono das antigas.

Duas grandes orientações se manifestaram, no pórtico dos' novos tempos: a empírica e a racional. Apesar de opostas, animavam-nas, como correntes de nova era, impulsos e características comuns: a) independência dos princípios clássicos, b) desejo de iniciar um novo edifício filosófico, sob novo estilo, diferente, se possível antagônico ao modêlo até então vigorante, c) separação absoluta entre a filosofia a teologia, d) abandono do latim, como "língua oficial" dos escritos filosóficos, e) ideal de multiplicação e disseminação da cultura filosófica.

As duas tendências, de que falamos acima, se corporificaram em Bacon e Descartes, naquele o empirismo, a experiência, como fonte exclusiva do conhecimento certo, como base única do conhecimento de tôda espécie, e, portanto, também do conhecimento filosófico, e neste, em Descartes, o racionalismo como fundamento da certeza, como critério do pensamento: a razão como sede e instrumento do verdadeiro conhecimento. Quanto mais racionais fôssem nossos pensamentos, mais certos poderiam ser.

Do empirismo de Bacon e do racionalismo de Descartes haveria de sair o material filosófico dominante nos séculos 17 e 18 . Do racionalismo se originaram vários sistemas, do empirismo derivaram o sensismo, o sensualismo, e o materialismo. As duas correntes, como signo visível da modernidade, ora correm paralelas, ora lutam, pela preponderância do pensamento e pela vitória de seus fundamentos.

Descartes impregnou de seu pensamento a França do século 18. Mesmo os escolásticos, tais como Bossuet e Fénelon, não se puderam furtar à sua influência. O ontologismo de Malebranche, o panteísmo de Spinosa, o dogmatismo de Leibniz pagam tributo sensível ao espírito cartesiano.

Bacon, por sua vez, também expandiu-se no tempo e no espaç. O seu empirismo derivou para o materialismo de Hobbes, embora Berkeley tente sistematizar-lhe os germes idealistas e Hume o faça descambar para o ceticismo. Com Locke, o empirismo se transforma em sensualismo, expresso por Condillac na França, de que se servem também os enciclopedistas.

Assim, pois, se extremaram as duas correntes iniciais, inaugura doras da filosofia moderna: o racionalismo conduziu ao "sono dogmático", enquanto o empirismo levou o pensamento aos princípios que informam o ceticismo. Criou-se, desta forma, um verdadeiro "impasse" para o desenvolvimento da perquirição filosófica. Tanto o racio- 
nalismo dogmático, como o empirismo cético nada podiam adiantar, para a história do pensamento. A filosofia estagnara. Era necessária uma construção nova. Ou, pelo menos, uma ponte das posições anteriores para novas posições que pudessem propiciar soluções diferentes. Os caminhos que deveriam ser evitados se apresentavam novamente. Foi aí que surgiu Kant. O criticismo, iniciado por Kant, procura dar solução ao problema. Foge à intenção dêste pequeno trabalho a exposição minuciosa da filosofia de Kant, mas apenas constitui seu objeto focalizar a influência kantiana na esfera do Direito, e, em especial, na renovação da Filosofia do Direito, começada em nossos dias, em pleno século 20.

Consoante a afirmação empírica, o criticismo entende também que todo conhecimento teórico deve ser construído sôbre a experiência. Mas o mundo externo não se reflete simplesmente sôbre os nossos sentidos, registrando-se em nossa inteligência. A influência do sujeito é ativa e decisiva. E' o sujeito o centro ativo do conhecimento. Conhece-se, sim, mas subjetivamente. Introduzindo, na categoria dos juízos, os juízos sintéticos "a priori”, distinguindo, em todo conhecimento, a matéria da forma, estabelecendo as formas de espaço e de tempo, como as condiçôes "a priori" da sensibilidade, cujo estudo denomina "estética transcendental", agrupando os conceitos "puros" do entendimento, relacionando-os com os juízos e as categorias, através do estudo a que denomina "analítica transcendental", e, finalmente, unificando a variedade dos juízos a um gráu superior, "a dialética transcendental”, Kant chega à exaustiva conclusão criticista: podemos ter um conhecimento, mas um conhecimeno informado pelas próprias leis de nossa organização espiritual. As formas "a priori" do conhecimento constituem a própria condicăo-limite de tôda experiência possível. Por isso, não nos é possível atingir o "noumenon", isto é, o "substractum", a própria realidade das coisas e dos sêres. Destarte, a metafísica não possui qualquer fundamento, e as ciências existem não pròpriamente como expressão da realidade, mas como a sujeição dessa realidade ao modo de ser cognoscitivo de nossa organização subjetiva. Se assim é no plano da razão pura, tanto não acontece no plano da razão prática. Neste plano, se restaura a metafísica, não como especulação racional, senão como obra de fé. O princípio informativo de tôda razão prática é a obrigatoriedade da lei moral. $O$ dever se impõe, com caráter de necessidade e universalidade, à nossa razão, como um verdadeiro imperativo categórico. Esta ordem de idéias, que, para Kant, estruturam a razão prática, não se modificam, não se alteram, ao ingressar no campo do Direito. Pelo contrário, irá êle aplicar as suas distincões ao fenômeno jurídico, e, embora não tenha sido um criador, na exata significação dêste têrmo, não se pode negar um certo aclaramento de posições, um determinado sucesso na noç̃o "ideal" de direito natura.
O individualismo de Rousseau tem em Kant, de certa forma, a sua tradução filosófica. Para ambos, o indivíduo é o centro. Daí Kant ter dado um novo aspecto à fundamentação do "Contrato Social" desligando-o do elemento histórico, para atê-lo apenas ao princípio "ideal". Aliás, esta similitude "mutatis mutandis" entre o filósofo da Revolução e o da Razão foi notada por diversos pensadores e juristas, entre êles Fouillée, Caird, Rensi, Boutroux, Le Fur, Del Vecchio.

"Kant realizou, na ordem especulativa, - assinala Del Vecchio - tarefa equivalente à realizada por Rousseau na ordem política. O sujeito, reconhecido já como princípio da ordem política, é agora também reconhecido como princípio na ordem da consciência. A Kant, assim o veremos, se ficou a dever esta conquista especulativa. Não foi Kant grande inovador nos domínios da Filosofia do Direito; a sua contribuição, aliás notável, consistiu, sobretudo, em corrigir em classificar pelo seu método rigoroso o antigo procedimento da escola de Direito natural. Na verdade, esta escola continha em si um princípio certo, a saber: o homem é a base do Direito. Aparentemente pelo menos, dera significado histórico ao que não passava de um princípio racional, considerara processo empírico o que era tão só processo ideológico. Veio assim quase a degenerar em mitologia, oferecendo bastantes motivos de irrisão. Mas, na realidade, partir do homem para chegar ao Estado, - entendido, êste, como a síntese dos direitos que se fundam na natureza humana, - é atitude justificada por razões profundas, as quais, até hoje, não foram rebatidas. Menos do que outros quaisquer as conseguiram repeiir os que cuidavam poder demolir com argumentos históricos o contrato social. A Kant, no campo da Filosofia do Direito, cabe o mérito de ter afirmado o valor puramente ideal (regulador) dos princípios do Direito natural, e, por conseguinte, de ter acabado com a confusão entre o histórico e o racional. Esta distinção já despontara, sem dúvida, em Locke e em Rousseau; mas, em ambos fôra indicada por uma forma que recordava o antigo equívoco e manteve-se latente. Desta sorte, de Kant recebeu a primeira afirmação explícita. Ele concebeu o contrato social, não já como fato histórico, realmente verificado, mas como pura idéia, que exprime o fundamento jurídico do Estado: é o seu arquétipo racional. E' costume designar estas correçóes metódicas dizendo: com Kant, acaba a escola do Direito natural (Naturrecht) e começa a escola do Direito racional (Vernuntrecht). O Direito natural passa a Direito da razão. Desnecessário é recordar, porém, que Kant mais não fêz do que ultimar um processo de correção metodológica, iniciada há muito e quase concluso com a obra de Rousseau". 
3 - Passemos, agora, a examinar outro ponto. Não só globalmente, exerceu Kant influência no Direito. No aspecto prático da crítica da razão, é que se poderá apreciar a conceituação formulada por Kant do fenômeno jurídico. Da importância e da obrigatoriedade da lei moral é que decorrem os fundamentos que dão origem à idéia do Direito. Vimos que, para o filósofo de Koenigsberg, não pode ter um conhecimento absoluto da realidade, porque o nosso conhecimento se processa através de formas "a priori", que não fazem parte da realidade, mas de nós mesmos. A realidade, como já foi dito, o "noumenon", é inatingível. As formas da sensibilidade e as categorias do entendimento não só se antepóem a tôda e qualquer experiência, como indicam também as suas condições limites. Assim, no aspecto teórico da razão, o nosso conhecimento está em relação com as condições cognoscitivas do próprio sujeito. Mas no aspecto prático da razão, pela obrigatoriedade da lei moral, o mesmo não acontece. Não podemos ser absolutos no conhecer, mas podemos ser absolutos no agir. O homem ativo pode alcançar o seu desiderato completo, absoluto. A lei do dever, pois, exerce sôbre nós um império fora de qualquer dúvida. Esta lei, que domina a razão prática, se expressa como "imperativo categórico", assim enunciado: "atua de tal modo que a máxima de teus atos possa valer como princípio de uma legislação universal". "A moral, nesta ordem, é o ponto máximo da construção kantiana. Da obrigatoriedade da lei moral, decorrem a liberdade, a existência de Deus, a imortalidade da alma. A lei moral, para Kant, é o primeiro grande princípio divisado pela razão prática. Por isso, é lógico que o seja mais amplo e profundo que o Direito. A moral ieva em conta os motivos, as "açoes internas", enquanto o direito só se preocupa com as "açôes externas", sem perquirir do motivo determinante das mesmas. Por isso, há, em Kant, uma certa oposição entre Direito e Moral. O Direito, confundindo-se com a liberdade ou não do agir, está sujeito à sanção, é coercível, ao passo que a moral, preocupando-se com os motivos íntimos, escapa a essa espécie de obrigatoriedade física. Assim define êle o Direito: "conjunto das condiçoes segundo as quais o arbítrio de cada um pode coexistir com o arbítrio dos restantes, de harmonia com uma lei universal de liberdade".

4 - A influência de Kant na Filosofia do Direito pode ser assim resumida:

1 - Como filósofo, criador de uma escola, harmonizador de tendências antagônicas do pensamento, como o empirismo, derivado de Bacon e degenerado em ceticismo, como o racionalismo, derivado de Descartes, degenerado em dogmatismo, exerceu, pela sua construção filosófica, uma influência direta no Direito, nos pontos já focalizados, e indireta na Filosofia do Direito, que, em seu tempo, se confundia com. Direito natural.

2 - Ainda como filósofo, criador de escola, o criticismo, exerceu uma influência indireta no Direito e no Direito natural em virtude da ação desenvolvida pelos seus discípulos e seguidores, entre os quais, de maior ou menor sujeição ao pensamento do mestre, podemos citar Fichte, Schelling e Hegel.

3 - Como alvo do retôrno ao Diretor natural, nos trabalhos preliminares de estruturação de uma nova Filosofia do Direito, após a longa noite positivista da segunda metade do século 19, exerceu uma grande influência na conceituação do Direito. Tôda a filosofia do Direito de nossos dias está impregnada do espírito do néokantismo, disseminado pelo grande iniciador da reação filosófica no direito: Stammler.

E' de notar-se, no entanto, que o próprio néo-kantismo é, freqüentemente, uma negação do próprio Kant. Por outro lado, a Filosofia do Direito de nossos dias já ultrapassou Kant tem quase todos os sentidos. Mas o velho filósofo alemão foi o foco, de cujo estudo partiu a nova orientação que haverı de suplantar as correntes naturalistas, cientificistas e positivistas em geral, dominantes em vários países, nos séculos 18 e 19, quando alcançou a sua maior esplendência. "Ao grito de Liebmann, acentua Cabral de Moncada, do "zurück zu Kant" (voltemos a Kant), de 1865 , sucedeu um estado de espírito que se poderia exprimir pelo grito precisamente oposto: fujamos de Kant. E' preciso reconhecer isto: a mais moderna filosofia ultrapassou Kant numa larga frente, e foge dêle. $E$, contudo, não menos notável: a influência e a sombra de Kant continuam a persegui-la. Hoje, como escreveu Ortega, as portas da "prisão kantiana" parecem, com efeito, abrir-se de par em par. Os presos evadem-se de lá um a um! E contudo êsses presos evadidos continuam a conservar cá fora, na liberdade, muitos dos hábitos contraídos na prisão". A volta a Kant, entretanto, foi o primeiro passo para a reação contra o agnosticismo positivista, o naturalismo e o cientificismo. Esta, precisamente, a grande influência indireta de Kant e direta dos néo-kantianos na Filosofia do Direito de nossos dias. Uma renovada conceituação do Direito, com vistas à filosofia jurídica, poderá negar Kant, poderá combatê-lo e até ultrapassá-lo, é natural. Mas não poderá negar que o progresso atual dos estudos de Filosofia do Direito muito deve ao criticismo, ao formalismo, tão ao sabor de Kant.

5 - Vejamos, sucintamente, para melhor ressaltar a influência de Kant, um trecho da história do pensamento jurídico, notadamente as transformações por que passou o Direito natural no século 19. Até então, não havia pròpriamente uma Filosofia do Direito. O que havia era, de um lado, o Direito positivo, a legislação, a lei escrita, freqüentemente obscura, injusta e autoritária, em que pese a influên- 
cia do direito romano. O Direito natural, anterior à conceituação de filosofia jurídica, era uma herança do pensamento clássico, caldeado pelo espírito religioso. "Ela (a idéia do Direito natural) não decorre da filosofia do século 18 que mais ou menos a deformou; procede antes de Grotius, e, antes dêle, de Suarez e Francisco Vitória; e, mais longe, de Santo Tomaz de Aquino, de S. Agostinho e de Padres da Igreja, e de São Paulo; e, mais longe ainda, de Cícero, dos Estóicos, dos grandes moralistas da antigüidade e de seus grandes poetas, de Sófocles, em particular. Antígona é a heroína eterna do direito natural, a que os Antigos chamavam a lei não escrita, nome, aliás, que melhor lhe convém". (Jacques Maritain). Ao lado das considerações anteriores, parece ter sido Aristóteles um dos que primeiro enunciou a distinção entre Direito natural e Direito positivo, ao estabelecer, em sua Ética, a diferença entre o justo por natureza e o justo por preceito legal. E durante mais de dois mil anos desenvolveu-se a idéia clássica, formulada sob fundamentos que repousam na própria natureza humana.

6 - No século 19, no entanto, como resultado da perquirição filosófica dos tempos modernos, e sob a influência das novas idéias, dominantes em vastos setores, notadamente da ciência, o Direito natural começou a sofrer as primeiras contestações. Karl Bergbohm foi dos seus grandes inimigos.

Invade o pensamento jurídico a escola histórica do. Direito. O grande vulto de Savigny estrutura-a em dois princípios básicos: a historicidade do Direito, negação do Direito natural; e a doutrina do espírito popular, como fonte criadora de todo Direito. A escola histórica, iniciada sob tão bons auspícios, sofre as mais variadas influências: de Hegel, que com seu idealismo, reduz a História à identidade do Espírito; a de Engels e Marx, que materializam o princípio hegeliano; a de Ihering, sob múltiplos aspectos, com o seu racionalismo histórico, o seu utilitarismo social e a sua orientação sociológica. Ao fio de tantos influxos, pouco restava da escola histórica, e o caminho estava preparado para o golpe de morte no Direito natural. Foi quando comecou a alastrar-se o positivismo sistematizado por Comte. O positivismo, por sua vez, se diversificou em quatro tendências distintas, cada qual exercendo sua influência no direito positivo. Tôdas estas influências, no entanto, afinavam por idênticos princípios diretivos, entre os quais o abandono dos estudos do Direito natural, o princípio da incognoscibilidade do mundo supra-sensível, em suma, o agnosticismo elevado à categoria de escola. Os quatro grandes ramos do positivismo (o sociológico com o próprio Comte, Durkheim, Gumplowicz, Schaffle; o histórico com Kohler, Felix Dahn; o psicológico com Zitelmann; o abstrato, na conceituação da teoria geral do Direito, principalmente com Adolf Merckel e E. R.
Bierling) insistem todos no objetivo comum de ter do Direito uma idéía geral advinda do estudo dos elementos históricos, dos dados sociológicos e da lei positiva. O Direito enquanto emoção, enquanto consciência pura do justo, enquanto idealidade, para o positivismo não existe, não participa do material com o qual, por via indutiva, irá elaborar uma síntese histórico-positiva do fato jurídico. $\mathrm{O}$ positivismo alcançou enorme significação em quase todos os países, principalmente França, Alemanha, Inglaterra, Itália. Entre nós, profunda e duradoura foi a influência do positivismo, a ponto de Del Vecchio, com a autoridade que todos lhe reconhecem, afirmar que "no Brasil, como aliás bem se compreende, dada a mocidade dêste formoso e riquíssimo país, é de recente data a atenção prestada aos estudos filosóficos do Direito. Só a partir de fins do século XIX, começaram a aparecer trabalhos notáveis sôbre os nossos temas. $\mathrm{O}$ momento em que surgiram, tornou-os contudo largamente tributários da corrente positivista, então uma das energias determinantes da cultura ocidental. A influência absorvente de Augusto Comte e seus epígonos franceses e inglêses, junto à recente e, por conseguinte, pouco sólida tradição jus-filosófica, explicam perfeitamente o desinterêsse manifestado pela maioria dos jurisconsultos brasileiros pela nossa disciplina. No campo da Filosofia do Direito, o Brasil não acordou ainda para o movimento de superação do positivismo sociológico, hoje batido em brecha pela maioria dos cultores de nossa disciplina, incluindo os da América Latina, nomeadamente os mexicanos e argentinos". Infelizmente, ainda nestes dias que correm, pouco diferentes poderiam ser as palavras de Del Vecchio. A reação filosófica, entre nós, ainda não aparece em tôda sua plenitude: Barros Lins, Hermes Lima, Pontes de Miranda ainda continuam, diretamente ou não, influenciados pelo positivismo ou seu espírito.

A maré cheia do comtismo há muito que já desapareceu. Na Europa e América, outras correntes, outras tendências vieram a lhe ocupar o lugar. A reação, no entanto, na filosofia jurídica, começou na segunda metade do século 19 e ampliou-se vitoriosamente no século presente. A volta a Kant foi, para Stammler, o ponto inicial, seguindo o conselho de Liebmann.

Interessante é notar a observação de Recasens Siches, sôbre os pródromos da restauração filosófico-jurídica: "Esa casi ausencia de Filosofia del Derecho en la segunda mitad del siglo XIX fué efecto de la tirania ejercida por el positivismo. Efectivamente, el positivismo habia invadido todos los campos científicos poniendo el veto radical a cuanto entranãse especulación ultraempírica. Tambien, por otra parte, se habia lanzado un anatema contra toda Filosofia jurídica, por el materialismo. Este, si bien radicalmente diverso del positivismo, en cuanto supone toda una Metafisica, aunque gratuita -

- R. D. - 3.0 Vol. 
que identifica la categoria de substancia con la materia - conduce en las disciplinas sociales a consequencias análogas a las del positivismo. En esa época, cuando alguna vez aparece el nombre de Filosofia juridica, êste encubre de ordinario sólo endebles sustitutivos de ella (historia, etnologia, enciclopedia, etc.)".

7 - Rodolfo Stammler (1856-1938) foi o grande jurista e filósofon que inaugurou a nova era para a Filosofia do Direito, após a enorme duração do interregno positivista, que registrou progressos para as. ciências particulares do Direito, mas que, indiscutivelmente, repre. sentou uma grande estagnação e mesmo um retrocesso no campo da perquirição filosófica.

Inaugurando a nova Filosofia do Direito, inaugurou, do mesma passo, o néo-kantismo. A tarefa do jurista alemão havia, de certo modo, sido favorecida pela escola do "Direito-livre", em cuja lista de vultos principais se alinham, entre outros, os de Kirchmann, Jellinek e Kantorowicz. O grande mérito, entretanto, ainda lhe assiste. de ter superado completamente o positivismo, que pràticamente desapareceu do âmbito da filosofia jurídica, subsistindo apenas como: um movimento histórico, para o estudo também histórico.

Desde cedo, preocupou-se Stammler em emprestar um cunho filosófico aos seus estudos jurídicos. Sua primeira obra de importância, publicada em 1888, se intitula "Do método da escola histórica do Direito", onde demonstra que a escola histórica, pelo seu método. e seu conteúdo, não esgota a realidade que deve servir de base, se se quiser elaborar um conceito filosófico do Direito. Em 1897, publica a primeira de suas grandes obras, "Direito e Economia", onde expõe e combate a teoria marxista do materialismo histórico e em que deixa. claros os princípios kantianos que, já nessa época, lhe informavam o pensamento. Em 1902, publica a segunda de suas grandes obras "A doutrina do direito justo", onde já revela em tôda plenitude estigma kantiano, quando expõe a sua concepção de idéia de justiça, "a priori”, universal e necessária, sob o ponto de vista formal, condição para submeter à experiência o próprio material social e histórico. As suas duas maiores obras, porém, são: "Teoria da Ciência Jurídica" e "Tratado de Filosofia do Direito".

O pensamento de Stammler, na Filosofia do Direito, pode ser resumido na determinação do conceito do Direito e na determinação do ideal jurídico, isto é, do direito justo. O primeiro problema - a determinação do conceito do Direito - é um problema lógico; o segundo problema - determinação do ideal jurídico - é um problema deontológico. Lidando já com o velho problema dos universais, abandonando o seu aspecto genético, firma-se apenas no aspecto de seu valor. Em ambos os casos, para a determinação do conceito e do ideal jurídico, apela para Kant: a universalidade e a necessidade são
- formalmente alcançadas, porque a experiência sendo particular e contingente não pode, por si só, fornecer conceitos universais e necessários. Com relação ao problema do direito justo, Stammler permanece inteiramente ligado a Kant, e são quase as mesmas as conceituações que ambos dão de Direito natural.

8 - A tradução latina da vocação kantista de Stammler, nos é dada por Giorgio del Vecchio, justamente considerado por Recasens Siches como o príncipe da Filosofia jurídica italiana. O idealismo crítico de Del Vecchio, embora inspirando-se em Stammler, apresenta diversos pontos de originalidade. Para o professor de Roma, a Filosofia do Direito se compóe de três partes distintas: uma lógica, uma segunda deontológica e uma terceira fenomenológica. A primeina parte, de acôrdo também com o pensamento de Stammler, consiste em saber o que é o Direito, em ter dêle um conceito lógico. E' o problema lógico. A segunda parte, tocante à determinação do ideal jurídico, consiste em indagar do direito justo. E' o problema deontológico, também comum em Stammler. Por fim, como resquício da influência positivista, Del Vecchio intercala, entre as duas partes filosóficas, uma outra fenomenológica, em que estuda a evolução histórica do fenômeno jurídico. Êste é o problema fenomenológico. Não se pode negar que a obra de Del Vecchio é mais completa que a de Stammler, embora baseada na dêste. Ambas possuem, principalmente com rellação ao problema lógico, profunda acentuação kantiana. Mas a realidade também é que ambas constituem o mais sério golpe recebido pelo positivismo e a maior tentativa, realizada em nossos dias, para a restauração da Filosofia do Direito.

Del Vecchio diverge de Stammler não só na conceituação do direito justo, como também na inclusão, no conteúdo da filosofia jurídica, do problema fenomenológico.

Interessante, e já como parte final dêste trabalho, será registar a definição que Del Vecchio dá ao Direito: "a coordenação objetiva das ações possíveis entre vários sujeitos, segundo um princípio ético que as determina, excluindo qualquer impedimento". A determinação dêste conceito é alcancado pela forma lógica do Direito, um dado "a priori”, a própria condição que torna possível tôda e qualquer experiência.

Em Stammler e Del Vecchio se reúnem os dois maiores néo-criticistas de nosso tempo; nêles também se sintetizam os grandes restauradores da Filosofia do Direito, que, hoje, já não se confunde com o Direito natural, embora êste seja uma de suas partes, e já vive vitoriosamente, na superação integral do positivismo.

E bem é que assim seja. Do estudo da Filosofia Jurídica muito hão de lucrar as novas mentalidades jurídicas de nossa terra. Como bem acentua Del Vecchio "os princípios imortais da liberdade e da 
igualçade humana, o ideal cosmopolítico de uma societas human generis, o direito imprescritível de qualquer povo a resistir e a insurgir-se contra os governantes opressores. Enquanto subsistir a tirania do homem sôbre o homem a Filosofia do Direito será uma philosophia
militans".

\section{RELATÓRIO E PARECER}

Relator: ARMANDO PEREIRA DA CAMARA

A tese apresentada pelo Dr. Delfim Mendes da Silveira sôbre a "INFLUENCIA DE KANT NA FILOSOFIA DO DIREITO", registra a superação do tratamento positivista do Direito, realizada pela
Filosofia de Kant.

A crítica kantiana, no entanto, libertando o Direito da interpretação simplista do Positivismo, aprisionou-o no plano de um logicismo desnaturante de sua realidade integral.

Não cremos, pois, que o pensamento jurídico moderno tenha realizado ascensões maiores, deixando de ser positivista para se fazer cri-
ticista.

Não obstante esta reserva crítica, como a tese constitui um lúcido registro dessa pseudo-superação, propomos aos srs. congressistas sua aprovação.

Pồrto Alegre, 16 de agôsto de 1950.

$$
\begin{aligned}
& \text { ARMANDO CAMARA } \\
& \text { SALGADO MARTINS } \\
& \text { ERNANI MARIA FIORI } \\
& \text { DARCY AZAMBUJA }
\end{aligned}
$$

\section{A FILOSOFIA DO DIREITO NO ENSINO JURÍDICO}

\section{Paulo Dourado de Gusmão}

Do Ministério Público da Justiça do Distrito Federal.

1 - A filosofia em nossa época tem despertado a atenção dos pensadores. Acentua-se, assim, em todos os setores do pensamento uma volta à filosofia, após a crise sofrida pelos estudos filosóficos no século passado. Vemos, dêste modo, desde o início do nosso século os pensadores, em face da crise do "cientismo" e do positivismo, voltarem-se para a filosofia em procura de uma solução racional para o universo.

A volta à filosofia refletiu, assim, a crise de uma cultura, do homem que se desiludiu da ciência e que desejava encontrar uma concepção do mundo que the proporcionasse paz espiritual.

$\mathrm{O}$ retôrno ao pensamento especulativo influiu, também, na jurisprudência. Assim, reagindo aos exageros do positivismo jurídico STAMMLER, na Alemanha, e DEL VECCHIO, na Itália, iniciaram, contemporâneamente, um movimento de renascimento da Filosofia do Direito, ao estabelecerem o a priori jurídico como condição, lògicatranscendental, do conhecimento jurídico e da possibilidade da ciência do direito ${ }^{(1)}$; com diversa orientação filosófica, os idealistas, influenciados pelas idéias de HEGEL, procuraram encontrar em uma peculiar atividade do pensamento a explicação ao "porquê" a experiência jurídica, diversa no tempo e no espaço, é sempre a mesma $\left({ }^{2}\right)$; houve, por sua vez, quem, como KELSEN, sofrendo a influência do positivismo procurara conciliá-lo com o néo-kantismo através a "pureza metódica" para constituir uma "teoria pura do direito" partindo do pres-

(1) DEL VECCHIO (G), I presupposti filosofici della nozione del diritto, Bologna, 1905; Id., Lezioni di Filosofia del Diritto, 7 ed. riveduta, Milano, 1950; STAMMLER (R), Economia y Derecho, Madrid, 1929, trad. hesp.; Tratado de Filosofia det Derecho,
Madrid, 1930, trad. hesp. (2) BINDER (J), La Fondazione della Filosofia del Diritto, Torino, 1945, trad.
CESARINI SFORZA (W), Guida allo Studio della Filosofia del Dirito, Roma, 1946; Id.,Corso di Filosofia del Diritto, Roma, 1947; OROCE, Riduzione della Fi-

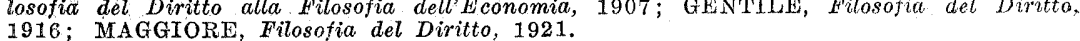

